\title{
A Review of Three Commonly Used Techniques of Controlling Greenhouse Microclimate
}

\author{
Mahesh Chand Singh ${ }^{1 *}$, J. P. Singh ${ }^{1}$, Sandeep Kumar Pandey ${ }^{1}$, Nikhil Gladwin Cutting ${ }^{1}$, \\ Pankaj Sharma ${ }^{1}$, Varun Shrivastav ${ }^{2}$ and Puneet Sharma ${ }^{1}$ \\ ${ }^{1}$ Department of Soil and Water Engineering, Punjab Agricultural University, \\ Ludhina-141004, Punjab, India \\ ${ }^{2}$ Department of Forestry and Natural Resources, Punjab Agricultural University, \\ Ludhina-141004, Punjab, India \\ *Corresponding author
}

\begin{abstract}
A B S T R A C T
The production potential of a crop grown inside a protective structure is directly associated with the microclimatic conditions offered to the crop. Thus, the microclimate should be

\section{Keywords}

Evaporative cooling,

Microclimate,

Natural ventilation,

Shading

Article Info

Accepted:

26 December 2017

Available Online:

10 January 2018 according to the crop grown for achieving the yield potential. Among the numerous available methods, natural ventilation, shading and evaporative cooling are three commonly used techniques for controlling the microclimate inside protective structures particularly under summer climatic conditions. Natural ventilation helps in dissipating the surplus heat and vapour through exchange between inside and outside air during summer. It excludes the excessive vapour and offers a suitable microclimate favourable to plant growth during winter. Shading has a positive impact on plant growth and development with reduced intensity of solar radiation and air temperature in plant community. Evaporative cooling helps in removing the sensible heat from interior of the protective structure. The greenhouse cooling efficiency can further be increased by combining evaporative cooling with reduced ventilation rate. Thus these techniques can be successfully adopted independently or in combination to obtain more efficient environmental conditions for optimal plant development and productivity.
\end{abstract}

\section{Introduction}

Microclimate is the assembly of the climatic parameters forming around living plants (Bailey 1985). It is strongly dependent on the outside conditions, particularly under unheated conditions. It directly affects the plant metabolic activities and therefore the production (Singh et al., 2006). It is a combination of physical processes involving energy and mass transport which are governed by environmental conditions, kind of structure, type of crop and state and effect of the control actuators (Bot 1983). In general, the greenhouse microclimate studies are undertaken to describe heat and mass exchange between plants, air and other surfaces. Thus, a better understanding of the 
relationships between plants and microclimatic parameters is extremely important (Bailey 1985, Singh et al., 2016) to offer most favourable conditions for improved plant growth and development under protective structures. Under hot climate, greenhouse cooling can be performed by different ways, either mechanically or naturally through wind and buoyancy (Willits 2003). Ventilation can be achieved by either by powered system (powered fans and intake vents) or passive ventilation (with no mechanical components i.e. no powered fans). Passive ventilation mainly takes place through convection (hot air becomes less dense and rises up) through ridge vents. Natural ventilation is the passive ventilation which can maintain optimum temperature and humidity range by replacing wet and warm air with dry and cool air. The microclimate inside a protective structure can be controlled by using three commonly techniques viz. natural ventilation, shading and evaporative cooling (fogging) independently or in combination.

\section{Greenhouse microclimate and its effect on crop growth}

The climatic parameters viz. Solar radiation, light, temperature, relative humidity, carbon dioxide concentration, vapour pressure deficit (VPD) and crop transpiration significantly affects the plant growth and development. Numerous other factors whoch affect the plant gowth and productivity are reported in Singh et al., (2017a).

\section{Solar radiation}

Solar radiation is the primary source of energy for greenhouse crop cultivation. It is one of the main climatic parameters needed to evaluate the suitability of climate of a region for protected cultivation. The least quantity of irradiation required for sufficient development and flowering corresponds to a daily global radiation in the range of $2.0-2.3 \mathrm{kWh} \mathrm{m}^{-2}$ day (Nisen et al., 1984). For cucumber plant, a solar radiation of $100.0-169 \mathrm{Wm}^{-2}$ has been suggested for optimal growth of cucumber inside a naturally ventilated greenhouse (Singh et al., 2017b).

\section{Light}

Light is a key parameters which significantly affect the greenhouse crop production (Wilson et al., 1992). Generally, three processes viz. photosynthesis, photoperiodism and photo morphogenesis are responsible for plant growth. Three kinds of light viz. Supplementary lighting can used to improve the yield when the light is not sufficient. Under hot climate, when light intensity becomes too high, shading can be performed (Stanghellini and Van Meurs 1992). Among these, photosynthesis is the most important process and plants use a maximum of $22.0 \%$ of the light absorbed in the region 400.0 to $700.0 \mathrm{~nm}$ (PAR) in the process of photosynthesis (Anon 2017b).

\section{Temperature}

The temperature distribution inside a greenhouse influences the uniformity of the crop growth (Sauser et al., 1998). The other climate parameters such as wind, temperature of growing media and composition of air influence to a lesser degree (Singh et al., 2017a). Temperature and relative humidity significantly affect the cucumber growth, development, quality and consequently the yield (Gajc-Wolska et al., 2008). Air temperature within plant community and rootzone temperature significantly affect the development and flowering of plants (Khah and Passam 1992) and thereby the crop yields (Pearson et al., 1995). Thus, limiting temperature to a desired range is of great importance for optimal crop growth (De Koning 1996). The temperature for optimum 
photosynthesis should lie between $21.0^{\circ} \mathrm{C}$ and $22.0^{\circ} \mathrm{C}$. The air temperature, leaf temperature and root-zone temperature should lie in the range of $22.0-27.0^{\circ} \mathrm{C}, \quad 20.5-25.1^{\circ} \mathrm{C}, \quad 16.9$ $22.9^{\circ} \mathrm{C}$ respectively for optimal growth and development of cucumber crop (Singh et al., 2017b).

\section{Relative humidity}

The relative humidity of the air within the plant community can be considered to be 100.0\% (Papadakis et al., 1994). However, the desired relative humidity for optimal growth of cucucmber plant lies in the range of 60.0$85.0 \%$ (Singh et al., 2017b). A value below $60.0 \%$ may result in plant water stress due to increased vapour pressure deficit or crop transpiration. On the other hand, a value greater than $85.0 \%$ for a long time especially during night may promote the incidence of fungus diseases. The relative humidity inside the protective structure can be maintained to desired range using ventilation during winter (reduction) and evaporative cooling during summer (increment).

\section{Carbon dioxide}

Carbon dioxide $\left(\mathrm{CO}_{2}\right)$ accumulated over the day is also an important variable which affects the plant growth in a greenhouse. It is an essential input parameter in photosynthesis process also significantly affects the greenhouse crop productivity (Rijkdjik and Houter 1993). Optimal $\mathrm{CO}_{2}$ concentration for the greenhouse crop production lies in the range 700.0-900.0 ppm (Tremblay and Gosselin 1998, De Pascale and Maggio 2008). When $\mathrm{CO}_{2}$ concentration is below the optimal range, $\mathrm{CO}_{2}$ enrichment can be achieved through a standard practice for maximizing productivity (Slack et al., 1988) and water use efficiency. A continuous increase in $\mathrm{CO}_{2}$ concentration inside the greenhouse at a regular interval may increase the fruit yield more than $20.0 \%$ for both fresh and dry matter (Sanchez-Guerrero et al., 2005).

\section{Vapour pressure deficit}

Vapour pressure deficit (VPD) is governed mainly by temperature, humidity and radiation level inside the solar greenhouses. It one of the parameters which affect the greenhouse crop transpiration (Jolliet and Bailey 1992) and therefore the irrigation management. It also affects the stomatal conductance of plant which plays an important role in the division of energy into sensible and latent heat (Choudhury and Idso 1985, Grantz and Zeiger 1986). The high VPD values may result in hampering of photosynthesis which in turn can limit the plant growth and dry matter accumulation and ultimately the yield. The mean fruit weight of cucumber gets reduced with an increase in VPD under high relative humidity (Bakker 1991). According to Singh et al., (2017b), vapour pressure deficit should lie in the range of $0.53-1.10 \mathrm{kPa}$ respectively for optimal growth and development of cucumber plant.

\section{Transpiration}

Transpiration which plays an important role in irrigation management under greenhouse cropped conditions (Baille et al., 1994) is linearly related to VPD even for higher values $(>2.5 \mathrm{kPa})$ (Lorenzo et al., 1998) or $(>3.0 \mathrm{kPa})$ Medrano et al., (2001, 2005). The increased transpiration particularly under hot climate may significantly increase the input irrigation water or nutrient solution. Thus, knowing transpiration may help to improve irrigation control in soilless cultivation of crops under greenhouse conditions (Medrano et al., 2005). Furthermore, transpiration is directly related to plant production (Watts and Goltz 1985) and merely $1.0 \%$ of the water taken by plants is utilized in metabolic activities (Rosenberg et al., 1983). Yang et al., (1990a) reported an 
average constant transpiration rate of $20 \mathrm{~g} \mathrm{~m}^{-2}$ $\mathrm{hr}^{-1}$ from cucumber crop during night. Transpiration is a key component of energy budget of a plant and a critical measure of yield. The plant development is directly correlated to water available to plant either in plant tissues or water vapour present in the surrounding air. Thus, monitoring and controlling water applied to a greenhouse plant, plant root water uptake, internal transport of water and external transport through transpiration becomes essential for optimal plant growth. Under cropped conditions, a fraction of the incoming solar radiation is utilized in the process of transpiration and sensible heat is transferred to latent heat. Transpiration is reliant on intensity of incoming solar radiation above the plant canopy, while photosynthesis is dependent on photosynthetically active radiation (0.4$0.7 \mu \mathrm{m}$ ) engrossed by the plant canopy (Kittas and Bailie 1998) and thereby shaping the overall productivity of the crop.

Numerous authors have studied the greenhouse microclimate in past (Slack and Hand 1981, van de Vooren 1981, Linker et al., 1999, Fatnassi et al., 2015, Li et al., 2017) and a few of them are discussed here. Slack and Hand (1981) investigated the response of cucumbers grown at night and day temperature in the range of $14.0-23.0^{\circ} \mathrm{C}$ and $16.0-25.0^{\circ} \mathrm{C}$. Early fruit yield increased with increasing night temperature up to $23.0^{\circ} \mathrm{C}$ and no increase was noticed at day temperature above $22.0^{\circ} \mathrm{C}$. The highest cumulative fruit yield was achieved at day or night temperature of $20.0^{\circ} \mathrm{C}$ (when day temperature was $20.0^{\circ} \mathrm{C}$ ) and at a day temperature of $22.0^{\circ} \mathrm{C}$ (when night temperature was $19.0^{\circ} \mathrm{C}$ ) after 20 weeks of picking. van de Vooren (1981) studied the effect of day and night temperature on earliness and production of a greenhouse winter cucumber crop from date of planting to start of production. According to the study, with an increase in night temperature from
12.0 to $20.0^{\circ} \mathrm{C}$, the earliness was decreased and a further increase till $24.0^{\circ} \mathrm{C}$ did not affect the earliness. Increasing day temperature from 20.0 to $26.0^{\circ} \mathrm{C}$ decreased the earliness. A positive effect on yield and production of cucumber was observed by increasing day temperature. Linker et al., (1999) conducted a study for controlling greenhouse air temperature and $\mathrm{CO}_{2}$ concentration by means of simultaneous ventilation and enrichment. The temperature was maintained by adjusting the ventilation and $\mathrm{CO}_{2}$ concentration was maintained through adjusting the enrichment. The $\mathrm{CO}_{2}$ concentration controller assumed a constant ventilation rate and roughly identified at an interval of two minutes. The execution in an experimental greenhouse proved the capability of the controllers to meet the requirements. Fatnassi et al., (2015) simulated distribution of solar radiation, thermal air, water vapour and the dynamic fields using the Computational Fluid Dynamic (CFD) model in two different prototypes of greenhouses (Asymmetric and Venlo) equipped with photovoltaic panels on their roof. Two arrangements of photovoltaic panels array were tested (straight-line and checkerboard) and the study comfirmed more even distribution of solar radiation in the Venlo type than Asymmetric greenhouse. The mean solar radiation transmission in Asymmetric and Venlo greenhouse was $41.6 \%$ and $46.0 \%$ respectively. The checkerboard photovoltaic panel setup improved the balance of the spatial distribution of sunlight than the straight-line arrangement. Li et al., (2017) evaluated the diurnal variations in temperature, relative humidity and solar radiation to analyze the microclimate inside different naturally ventilated single-sloped greenhouses. The study showed that greater height and shorter span facilitated energy conservation and saving in single-sloped greenhouses. This study provided a reference for further research to save energy, to achieve appropriate greenhouse microclimate for 
improved quality, improved yield and shorter duration of cultivation in single-sloped greenhouses.

\section{Methods of controlling greenhouse microclimate}

There are several methods to control the greenhouse microclimate depending upon the outside climatic conditions of the area (Table 1). These methods include the microclimate control through cooling during summer and heating during winter climates respectively. The present study has mainly focused on reviewing the three commonly used techniques viz. natural ventilation, shading and evaporative cooling (fogging or misting) for controlling greenhouse microclimate.

Microclimate control through natural ventilation, shading and evaporative cooling

Protected cultivation is an efficient and feasible option, especially for the sustainable vegetable production in the regions of unfavorable climatic conditions. Temperature is considered as one of the main factors affecting the greenhouse crop productivity and quality. However, there are several factors such as ventilation rate, crop evapotranspiration, shading, evaporation from the wet pads (if any) and coefficient of heat loss from the cover affecting the greenhouse temperature distribution (Kittas et al., 2003). Inside a protective structure, the choice of a cooling method during summer climate depends on many aspects, such as local climatic conditions, agronomic practices, design and covering materials. To achieve desirable benefits, the different cooling methods (natural ventilation, evaporative cooling and shading) can be used independently or in combination to create the most encouraging environment for plant growth. The main reason for microclimate control in greenhouses is to achieve desirable plant growth and yield. A better control on greenhouse microclimate may help in extending the length of growing season in addition to improved fruit yield and quality (Bailley 2000).

\section{Advantages of protected cultivation}

Offers an optimal growing environment for plant growth

Reduction in incidence of insect-pest or diseases

Faster growth

Allows year-round cultivation

Distinct advantage of productivity and quality compared to open field cultivation

Increased duration of crop season

Encouraging market price to the growers

Reduced application of agricultural chemicals

Reduces consumption of water and nutrients

\section{Natural ventilation}

Natural ventilation is the cheapest, simplest and most energy efficient method of controlling microclimate inside a greenhouse in comparison to mechanical system (FloresVelazquez et al., 2011). In summer, natural ventilation helps in dissipating surplus heat and vapour through exchange between inside and outside air, while it can exclude excessive vapour and provide a suitable thermal climate in winter (Baptista et al., 1999). A naturally ventilated greenhouse works effectively in temperature range of $15.0-35.0^{\circ} \mathrm{C}$ (Marcelis and de Koning 1995). Ventilation plays a significant role in greenhouse cooling by 
replacing the inside warm air with outside cold air and consequently maintaining the inside temperature. Cooling through ventilation has always been an important problem for greenhouse operator in warm climates, potentially limiting production and constraining profits. Natural ventilation directly affects the crop growth and development in relation to the factors such as temperature, humidity and $\mathrm{CO}_{2}$ concentration (Kittas et al., 1996).

A naturally ventilated greenhouse allows realization of economic yield at a lower production cost (Enoch 1986). Wind and stack effect are the two main driving forces of natural ventilation (Baptista et al., 1999). The efficiency of natural ventilation is dependent on the parameters such as speed and direction of wind, inside-outside temperature difference, presence or absence of a crop and the design of a greenhouse (Ould-Khaoua et al., 2006). The poor ventilation has a negative effect on air composition inside the greenhouse chiefly due to reduction in $\mathrm{CO}_{2}$ concentration (Lorenzo et al., 1990).

The ventilation helps in mainaining an encouraging environment for plant growth and development (Hermanto et al., 2006) and can be performed from sides and the roof for a naturally ventilated greenhouse. According to Teitel et al., (2006), the combination of roof and side vents is more efficient methods in reducing inside humidity and temperature compared to roof-alone ventilation at a lower air flow resistance of side vents. According to Mutwiwa et al., (2008), in areas with high ambient humidity and solar radiation levels, the combination of natural ventilation and NIR-reflection may help in cooling the greenhouses. Vapour pressure transport and transpiration are closely related to each other and increase with rate of ventilation (Bakker 1984). The ventilation rate is dependent on wind speed and size of opening of vent (Fatnassi et al., 2002) and wind direction
(Teitel et al., 2008). In past, numerous authors studied the effect of vent types and insect nets on greenhouse ventilation rate (Kittas et al., 2005). Authors also made the attempts to model the ventilation of greenhouse (Fatnassi et al., 2002, Romero et al., 2006, Impron et al., 2007).

A continuous effort has been made by the researchers to study the greenhouse ventilation under different crop and climatic conditions globally (Bakker 1984, Fatnassi et al., 2002, Kittas et al., 2005, Berenguel et al., 2006, Hermanto et al., 2006, Romero et al., 2006, Teitel et al., 2006, Kittas et al., 2008, Mutwiwa et al., 2008, Teitel et al., 2008, Yang et al., 2008, Villarreal-Guerrero et al., 2014).

Bakker (1984) studied the effects of a sudden increase in ventilator aperture of greenhouse from 0.0 to $60.0 \%$ on performance of cucumber crop. According to the study, the crop transpiration and water vapour transport increased from 3.0 to $12.0 \mathrm{~g} \mathrm{~m}^{-2} \mathrm{~min}^{-1}$ and 1.0 to $28.0 \mathrm{~g} \mathrm{~m}^{-2} \mathrm{~min}^{-1}$ due to decrease in temperature and specific humidity with opened ventilatiors. Leaf burning occurred around the petiole due to loss of water because of increased transpiration in the upper layers of the crop. Ruther (1985) carried out a study to measure natural ventilation of closed greenhouses in relation to wind velocity, wind direction and difference in inside-outside air temperature. The study investigated a simple and efficient method for tightening leakages. Fatnassi et al., (2002) examined the ventilation performance of a large Canariantype greenhouse equipped with insect proof nets on the vent openings. The air exchange rate was measured by means of tracer gas method under cropped condition. A model of ventilation was worked out and the model simulation indicated an increased ventilation rate proportionally with wind speed and size of opening for a given wind direction. The 
insect-proof net induced a strong additional pressure drop through the opening which significantly reduced the ventilation rate and increased the greenhouse air temperature. The model was further used for studying the effects of anti-thrip and anti-aphid nets on the greenhouse ventilation and the resulting climate.

Table.1 Methods of controlling microclimate under a protective structure

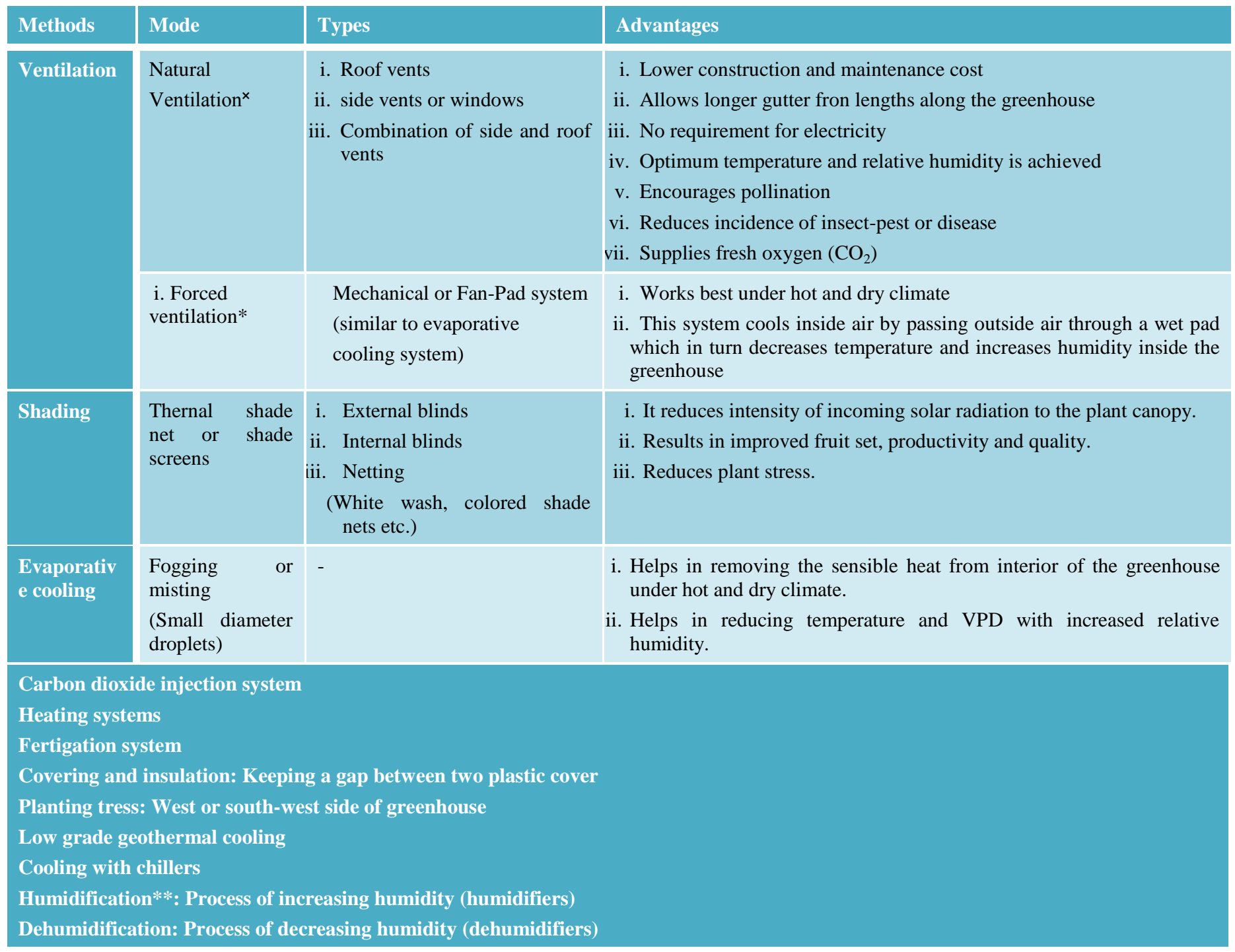

Kittas et al., (2005) investigated the influence of vent type and of insect proof screens on ventilation rate of a round arch plastic greenhouse. Microclimatic parameters and the greenhouse ventilation rate $(G)$ were measured. $G$ was determined by two methods viz. the decay rate tracer gas method using $\mathrm{N}_{2} \mathrm{O}$ as tracer gas and the greenhouse energy balance method. The ventilation was performed from roof only, side only and both roof and side vents. The study concluded tracer gas method as a better fit to the experimental data and the combination of roof and side vents as the most effective vent configuration. Berenguel et al., (2006) developed a kind of feedback linearizing controller for a parral-type greenhouse for control of diurnal temperature through natural 
ventilation. The controller represented a dynamical combination of feedback-feed forward control where unmodelled dynamics can be partially compensated by feedback. Hermanto et al., (2006) optimized the greenhouse ventilation area in a naturally ventilated greenhouse under cropped condition and reported that the ventilation area of $60.0 \%$ provided at ridge and sides was capable of maintaining an encouraging greenhouse environment throughout the year for crop growth.

Romero et al., (2006) studied the ventilation rate through optimization of greenhouse design constraints (area of inlet and outlet vents) and type of the insect screen using a Computational Fluid Dynamics (CFD) approach. The study indicated a significant effect of ventilation openings on the air exchange rate which increased by $25.0 \%$ with an increase in vent area (6.0 to $15.0 \%$ of the greenhouse ground area). Teitel et al., (2006) studied the effect of the resistance to air flow through the roof and side vents on the microclimate and ventilation inside a multi span greenhouse under cropped condition. The study reported roof and side vents combination as more efficient in reducing humidity and temperature compared to roofalone ventilation system at a low airflow resistance of the side vents. Kittas et al., (2008) investigated the influence of vent type and anti-aphid insect screens on air flow, air temperature and vapor pressure deficit (VPD) distribution inside a mono-span greenhouse with vertical side walls under cropped condition.

\section{Disadvantages of natural ventilation ${ }^{\times}$}

Internal climate is highly dependent on external climate

Difficult to determine and control the internal climate due to increased variability
Dehumidification** can be achienved as

Combining heating with ventilation system

Condensation on cold surfaces

Forced ventilation in combination with heat exchangers

Using anti-drop covering materials

Absorption using hygroscopic material

The normalized air velocity was $58.0 \%$ lower in the greenhouse with insect screens on the side vent openings than without screens and the most uniform climatic conditions were achieved using roof openings only. The study provided a better understanding of the plant environment under different vent configurations and a high-resolution database for validating on-going efforts with computer simulations.

Mutwiwa et al., (2008) investigated the effect of near infra-red (NIR) reflecting pigments on the greenhouse microclimate and plant growth in two naturally ventilated greenhouses provoided with insect-proof nets on the sidewalls and roof ventilation openings. According to the study, the combination of natural ventilation and NIR-reflection may provide a solution for cooling greenhouses in areas with high ambient humidity and solar radiation levels. Teitel et al., (2008) investigated the effect of wind direction on air flow patterns and air temperature distributions in a naturally ventilated greenhouse with vertical roof openings using computational fluid dynamics technique (CFD). The study indicated a significant effect of the wind direction on ventilation rate, airflow and crop temperature distributions. The observed ventilation rates were in good agreement with predicted ventilation rates. Yang et al., (2008) numerically investigated the microclimate 
inside four single span greenhouses using a commercial Computational Fluid Dynamics (CFD) package. The three-dimensional simulations were compared with experimental data and a good agreement was obtained. The ventilation rate and temperature distribution at different wind speeds were analyzed on the basis of numerical results. The study indicated that the ventilation rate of greenhouses was strongly affected by its relative location to wind direction (windward or leeward). Villarreal-Guerrero et al., (2014) tested a greenhouse cooling strategy through computer simulation inside a natural ventilated greenhouse. The strategy used set points of air specific enthalpy $\left(55.8 \mathrm{~kJ} \mathrm{~kg}^{-1}\right)$ and vapor pressure deficit $(\mathrm{VPD}=1.0 \mathrm{kPa})$ of the greenhouse air to control ventilator openings and fog rates to maintain an air temperature and relative humidity of $24.0^{\circ} \mathrm{C}$ and $66.5 \%$ respectively. The study indicated that the strategy was capable of maintaining the set points when cooling demands were present in the greenhouse regardless of the location and outside climate.

\section{Shading}

Greenhouse shading can be used to control the entry of unwanted radiation (Hashem et al., 2011). Shading favours the plant growth (Hashem et al., 2011) and development irrespective of nutrients applied (Patil and Bhagat 2014) thereby enhancing the yield of greenhouse cucumbers (Lorenzo et al., 2006). Shading has a positive impact on greenhouse crop production, quality and homogeneity (Briassoulis et al., 2007). It helps in reducing the plant stress, intensity of sunlight entering the greenhouse, temperature with increased humidity and evapotranspiration (Hashem et al., 2011). It is found more efficient in hot and sunny regions (Al-Helal and AbdelGhany 2010). Shaded cucumber plants grow taller than unshaded plants and produce a greater average internode length (El-Abd et al., 1994). Therefore, the quality of the solar radiation allowed by covering materials to enter the greenhouse is important for evaluating its influence on plant growth and development (Kittas et al., 1999). The greenhouse shading also helps in reducing the crop temperature and the rate of transpiration (Dayan et al., 2000). Under hot climate, shading can also be applied over a greenhouse to improve the fruit set, yield and quality (Gent 2008). Conversely, under mild climate, the yield of greenhouse vegetable crops normally reduces with shading (Cockshull et al., 1992). Sumathi et al., (2008) reported a positive effect of shading on growth and yield parameters in cucumber. Kittas et al., (2009) also reported a $50.0 \%$ higher marketable production of tomato under shaded conditions than non-shaded conditions. Similarly, Hashem et al., (2011) reported the best crop yield by using white net house. However, Gent (2008) reported a 30.0\% reduction in crop yield with shading for six weeks than without shading. Similarly, Siwek et al., (2010) reported the lowest yield of cucumber under shaded conditions. Shading can be achieved by limiting the light that directly reaches the plants (Siwek and Lipowiecka 2004).

Several studies in the past reported the effects of shading on crop yield and quality (Medany et al., 1999, Kittas et al., 2009, Patil and Bhagat 2014, Teitel et al., 2012).

Medany et al., (1999) studied the effect of night-set temperature, shading and season on growth rate of cucumber fruit. The study included two treatments of shading (shading with $33.0 \%$ black shade net and double polyethylene greenhouse without shading), two set point temperatures $\left(10.0\right.$ and $\left.18.0^{\circ} \mathrm{C}\right)$ and two seasons. The study reported highest fruit growth rate without shading at night-set temperature of $18.0^{\circ} \mathrm{C}$ during both seasons. Kittas et al., (2009) conducted field 
experiments to study the influence of four different shading screens on microclimate, growth and productivity of the crop grown. The canopy temperature and air vapour pressure deficit were significantly lower under the shading nets than the open field. The study indicated an increased leaf area index and total marketable yield with shading and reduced fruit cracking of about $50.0 \%$. The marketable production was $50.0 \%$ higher under shaded than non-shaded conditions.

Kitta et al., (2012) investigated the effect of greenhouse shading and irrigation water salinity on greenhouse microclimate, energy balance, crop transpiration and leaf photosynthesis in three similar plastic greenhouses with cucumber cultivated in hydroponic system. Two greenhouses were shaded using two different shading nets with shading intensity of 35.0 and $50.0 \%$ and the third greenhouse was taken as a control. Two levels of salinity were applied in each greenhouse (2.3 and $6.3 \mathrm{dS} \mathrm{m}^{-1}$ ). The study reported no significant effect of shading on greenhouse air temperature. However, the leaf photosynthesis and transpiration rate were reduced with shading with no significant effects of salinity. Teitel et al., (2012) used shading net $(30.0 \%)$ above the greenhouse on top of the polyethylene cover in one compartment (three spans). In second compartment (three spans), the net was stretched horizontally inside the compartment at gutter height in the second compartment. According to the study, the net position with a shading less than or equal to $30.0 \%$ did not significantly affect the greenhouse microclimate. Patil and Bhagat (2014) studied the yield response of cucumber grown under $35.0 \%, 50.0 \%$ and $75.0 \%$ shading and in open field condition. The study confirmed a better performance of crop grown inside the shade net than open field conditions irrespective of the nutrients applied.

Evaporative cooling (fogging)
The evaporative cooling helps in removing the sensible heat from interior of the protective structure with best working under hot and dry climate for the maximum evaporative cooling (Chung et al., 2010). The greenhouse cooling efficiency can further be increased if evaporative cooling is combined with a reduced ventilation rate $(\mathrm{Li}$ et al., 2006). Fogging system is based on spraying water in small droplets of diameter of $2.0-60.0 \mu \mathrm{m}$ with high pressure nozzles. In fogging, cooling is achieved by evaporation of droplets which in turn helps in increasing the relative humidity apart from cooling the greenhouse. Cooling air is desirable under several greenhouses to reduce the plant stress and improve the marketable quality of production (Nelson 1996). Evaporating cooling is one of the methods which help in lowering the temperature with an increase in humidity thereby reducing the vapour pressure deficit and transpiration (Arbel et al., 1999, Willits 1999, Katsoulas et al., 2001).

Several researchers adopted evaporating cooling (fogging) as a cooling method inside the protective structures (Arbel et al., 1999, Ozturk 2003, Gazquez et al., 2008, Li and Wang 2015)

Arbel et al., (1999) tested the efficiency of the fog system with a droplet size of $2.0-60.0 \mu \mathrm{m}$ inside a greenhouse through a comparison between the results of fog system and fan-pad system. The study concluded fog system as superior than fan-pad system when temperature and relative humidity variations were less than $5.0^{\circ} \mathrm{C}$ and $20.0 \%$ respectively. Ozturk (2003) investigated the efficiency of fogging system (FS) inside a multi-span (11 spans) plastic greenhouse (PG). Three nozzle lines with 82 fog generating nozzles (FGN) operating at a pressure of 4.5 atm were installed in each span of the PG. The FS helped in keeping the air temperature inside 
the PG $6.6{ }^{\circ} \mathrm{C}$ lower than the outside with an efficiency of $11.7-80.0 \%$. The relative humidity inside the PG was increased by $25.0 \%$ by means of the FS system. Fogging system efficiency (FSE) increased linearly with evaporation flow rate and absolute humidity difference (AHD) between the inside and outside air.

Gazquez et al., (2008) evaluated different cooling strategies viz. white washing, fogging, natural or forced ventilation and their effects on the microclimate, growth and yield of crop grown in three multi-tunnel greenhouses. Fogging was the most efficient method in controlling the maximum temperature and VPD values. The combination of whitening of the plastic cover and natural ventilation was the most efficient cooling system in terms of water and energy use. Li and Wang (2015) discussed some applicable and practical cooling technologies, reporting evaporation cooling as the most effective cooling method for controlling the temperature and humidity inside a greenhouse. According to the study, the shade net application with different perforated mesh size and their evaluation with respect to local climate and region are necessary to get cooling benefits in summer.

Natural ventilation, shading and evaporative cooling (fogging) are three engineering techniques commonly used worldwide for controlling the microclimate inside protective structures under cropped conditions. These techniques affect the greenhouse microclimate in a positive manner and can be successfully adopted independently or in combination to obtain more efficient environmental conditions for optimal plant development and productivity.

\section{References}

Al-Helal A M, Abdel-Ghany I M 2010. Responses of plastic shading nets to global and diffuse PAR transfer: Optical properties and evaluation. NJASWageningen J Life Sci 57:125-32.

Anonymous, 2017b. Management of greenhouse environment. Available at http://www1.

agric.gov.ab.ca/\$department/deptdocs.nsf/ all/opp2902. [Accessed on 06.06.2017 at 22:26 pm]

Arbel A, Yekutieli O and Barak M 1999. Performance of a fog system for cooling greenhouses. J Agric Eng Res 72:129-36.

Bailey B J 1985. Microclimate, physical processes and greenhouse technology. Acta Hort 174:35-42.

Bailey B J 2000. Constraints, limitations and achievements in greenhouse natural ventilation. Acta Hort 534:2-30.

Baille M, Baille A and Laury J C 1994. A simplified model for predicting evapotranspiration rate of nine ornamental species vs. climate factors and leaf area. Sci Hort 59:217-32.

Bakker J C 1984. Effects of changes in ventilation on cucumber. Acta Hort 148:519-24

Bakker J C 1991. Leaf conductance of four glasshouse vegetable crops as affected by air humidity. Agric For Meteorol 55:2336.

Baptista F J, Bailey B J, Randall J M and Meneses J F 1999. Greenhouse ventilation rate: Theory and measurements with tracer gas techniques. J Agric Eng Res 72:363-74.

Berenguel M, Rodriguez F, Guzman J L, Lacasa D and Perez-Parra J 2006. Greenhouse diurnal temperature control with natural ventilation based on empirical models. Acta Hort 719:57-64.

Bot G P A 1983. Greenhouse climate from physical processes to a dynamic mode. Ph.D. dissertation. Agricultural University of Wageningen, The Netherlands.

Briassoulis D, Mistriotis A, Eleftherakis D 2007. Mechanical behaviour and properties of agricultural nets - Part I: Testing methods for agricultural nets. Polymer Testing 26:822-32. 
Choudhury B J and Idso S B 1985. An empirical model for stomatal resistance of field-grown wheat. Agric For Meteorol 36:65-82.

Chung M, Liao S and Tin S 2010. Characterizing the performance of alternative cooling pad media in thermal environmental control applications, Taiwan 10617, Republic of China.

Cockshull K E, Graves C J and Cave C R J 1992. The influence of shading on yield of glasshouse tomatoes. J Hort Sci 67:1124.

Dayan E, Fuchs M, Plaut Z, Presnov E, Grava A, Matan E, Solphoy A, Mugira U and Pines N 2000. Cooling of roses in greenhouses. Acta Hort 534:351-60.

De Koning A N M 1996. Quantifying the responses to temperature of different plant processes involved in growth and development of glasshouse tomato. Acta Hort 406:99-104.

De Pascale S and Maggio A 2008. Plant stress management in semiarid greenhouse. Acta Hort 797:205-15.

El-Abd M T G, Shanan S A, Abou-Hadid A F and Saleh M M 1994. Effect of different shading densities on growth and yield of tomato and cucumber. Egypt $J$ Hort 21:64.

Enoch H Z 1986. Climate and protected cultivation. Acta Hort 176:11-20.

Fatnassi H, Boulard T, Demrati H, Bouirden L and Sappe G 2002. Ventilation performance of a large Canarian-type greenhouse equipped with insect-proof nets. Biosyst Eng 82:97-105.

Fatnassi H, Poncet C, Bazzano M M, Brun R and Bertin N 2015. A numerical simulation of the photovoltaic greenhouse microclimate. Sol Energy 120:575-84.

Flores-Velazquez J, Mejia, E, Montero J I and Rojano A 2011. Numerical analysis of the inner climate in a mechanically-ventilated greenhouse with three spans. Agrociencia 45:545-60.

Gajc-Wolska J, Bujalski D and Chrzanowska A 2008. Effect of a substrate on yielding and quality of greenhouse cucumber fruits. J Elementol 13:205-10.

Gazquez J C, Lopez J C, Perez-Parra J J, Baeza E J, Saez M and Parra A 2008. Greenhouse cooling strategies for mediterranean climate areas. Acta Hort 801:425-32.

Gent M P N 2008. Density and Duration of Shade Affect Water and Nutrient Use in Greenhouse Tomato. J Am Soc Hort Sci 133:619-27.

Grantz D A and Zeiger E 1986. Stomatal responses to light and leaf-air water VPD show similar kinetics in sugarcane and soybean. Plant Physiol 81:865-68.

Harmanto L, Tantau H J and Salokhe V M 2006. Optimization of ventilation opening area of a naturally ventilated greenhouse in humid tropical environment. Acta Hort 719:165-72.

Hashem F A, Medany M A, Abd El-Moniem E $\mathrm{M}$ and Abdallah M M F 2011. Influence of greenhouse cover on potential evapotranspiration and cucumber water requirements. Ann Agric Sci 56:49-55.

Impron I, Hemming S and Bot G P A 2007. Simple greenhouse climate model as a design tool for greenhouses in tropical low land. Biosyst Eng 98:79-89.

Jolliet O and Bailey B J 1992. The effects of climate on tomato transpiration in greenhouses: measurements and models comparison. Agric For Meteorol 58:4362.

Katsoulas N, Baille A and Kittas C 2001 Effect of misting on transpiration and conductance of a greenhouse rose canopy. Agric For Meteorol 106:233-47.

Khah E M and Passam H C 1992. Flowering, fruit set and development of the fruit and seed of sweet pepper (Capsicum annuum L.) cultivated under conditions of high ambient temperature. J Hort Sci 67:25158.

Kitta E, Bartzanas T, Savvas D and Katsoulas N 2012. Effect of shading on greenhouse energy balance and crop transpiration. Acta Hort 927:689-94.

Kittas C, Baille A and Giaglaras P 1999. Influence of covering material and 
shading on the spectral distribution of light in greenhouses. J Agric Eng Res 73:341-51.

Kittas C, Bartzanas T and Jaffrin A 2003. Temperature gradient in a partially shaded large greenhouse equipped with evaporative cooling pads. Biosyst Eng 85:87-94.

Kittas C, Boulard T, Mermier M and Papadakis G 1996. Wind induced air exchange rates in a greenhouse tunnel with continuous side openings. J Agric Eng Res 65:37-49.

Kittas C, Katsoulas N, Bartzanas T, Boulard T and Mermier M 2005. Effect of vents' opening and insect screen on greenhouse ventilation. Proc International Conference on Passive and Low Energy Cooling for the Built Environment. pp 5964. Santorini, Greece.

Kittas C, Katsoulas N, Bartzanas T, Mermier M and Boulard $\mathrm{T}$ 2008. Openings on the greenhouse microclimate. Am Soc Agric Bio Eng 51:1-15.

Kittas C, Rigakis N, Katsoulas N and Bartzanas $\mathrm{T}$ 2009. Influence of shading screens on microclimate, growth and productivity of tomato. Acta Hort 807:97-102.

Li A, Huang L and Zhang T 2017. Field test and analysis of microclimate in naturally ventilated single-sloped greenhouses. Energy Build 138:479-89.

Li H and Wang S 2015. Technology and studies for greenhouse cooling. World J Eng Technol 3:73-77.

Li S, Willits D H and Yunker C A 2006. Experimental study of a high pressure fogging system in naturally ventilated greenhouses. Acta Hort 719:393-400.

Linker R, Gutman P O and Seginer I 1999. Robust controllers for simultaneous control of temperature and $\mathrm{CO}_{2}$ concentration in greenhouses. Control Eng Prac 7:851-62.

Lorenzo P, Garcia M L, Sanchez-Guerrero M C, Medrano E, Caparros I and Gimenez M 2006. Influence of mobile shading on yield, crop transpiration and water use efficiency. Acta Hort 719:471-78.

Lorenzo P, Medrano E and Sanchez-Guerrero
M C 1998. Greenhouse crop transpiration: an implement to soilless irrigation management. Acta Hort 458:113-22.

Lorenzo P, Sanchez-Guerrero M C, Medrano E, Perez J and Castilla N 1999. Soilless cucumber response to mulching in an unheated mediterranean greenhouse. Acta Hort 491:401-04.

Marcelis L F M and de Koning A N M 1995. Biomass Portioning in Plants. In: Greenhouse Climate Control: An Integrated Approach. Pp 84-92. Wageningen Press, Netherlands.

Medany M A, Wadid M M and Abou-Hadid A $F$ 1999. Cucumber fruit growth rate in relation to climate. Acta Hort 491:107-12.

Medrano E, Lorenzo P and Sanchez-Guerrero M C 2001. Evaluation of a greenhouse crop transpiration model with cucumber under high radiation conditions. Acta Hort 559:465-70.

Medrano E, Lorenzo P, Sanchez-Guerrero M C and Montero J I 2005. Evaluation and modelling of greenhouse cucumber-crop transpiration under high and low radiation conditions. Sci Hort 105:163-75.

Mutwiwa U N, von Elsner B, Tantau H J and Max J F J 2008. Cooling naturally ventilated greenhouses in the tropics by near-infra red reflection. Acta Hort 801:259-66.

Nelson P V 1996. Greenhouse operation and management. Third edition, Prentice-Hall, Inc., New Jersey 07632.

Nisen A, Sirjacobs M and von Zabeltitz C 1984. Protected cultivation in Mediterranean climate, greenhouses in Egypt. FAO, Rome.

Ould Khaoua S A, Bournet P E, Migeon C, Boulard T, Chasseriaux G 2006. Analysis of green-house ventilation efficiency based on computational fluid dynamics (CFD). Biosyst Eng 95:83-88.

Ozturk H H 2003. Evaporative cooling efficiency of a fogging system for greenhouses. Turk J Agric For 27:49-57.

Papadakis G, Frangoudakis A and Kyritsis S 1994. Experimental investigation and modelling of heat and mass transfer 
between a tomato crop and the greenhouse environment. J Agric Eng Res 57:217-27.

Patil M A and Bhagat A D 2014 Yield response of cucumber (Cucumis sativus L.) to shading percentage of shade net. Int $J$ Agric Eng 7:243-48.

Pearson S, Hadley P and Wheldon A E 1995. A model of the effect of day and night temperature on the height of chrysanthemum. Acta Hort 378:71-80.

Reyes-Rosas A, Molina-Aiz F D, Valera D L, Lopez A and Khamkure S 2017. Development of a single energy balance model for prediction of temperatures inside a naturally ventilated greenhouse with polypropylene soil mulch. Comput Electron Agric 142:9-28.

Rijkdijk A A and Houter G 1993. Validation of a model for energy consumption, $\mathrm{CO}_{2}$ consumption and crop production (ECPmodel). Acta Hort 328:125-31.

Romero P, Giacomelli G A, Choi C Y and Lopez-Cruz I 2006. Ventilation rates for a naturally-ventilated greenhouse in central mexico. Acta Hort 719:65-72.

Rosenberg N J, Bald B L and Verma S B 1983. Microclimate: The Biological Environment. $\quad 2^{\text {nd }} \quad$ edn., Wiley Interscience, p 495.

Ruther M 1985. Natural ventilation rates of closed greenhouses. Acta Hort 170:18592.

Sanchez-Guerrero M C, Lorenzo P, Medrano E, Castilla N, Soriano T and Baille A 2005. Effect of variable $\mathrm{CO}_{2}$ enrichment on greenhouse production in mild winter climates. Agric For Meteorol 132:244-52.

Sauser B J, Giacomelli G A and Janes H W 1998. Modelling the effects of air temperature perturbations for control of tomato plant development. Acta Hort 456:87-92.

Singh G, Singh P P, Lubana P P S and Singh K $G$ 2006. Formulation and validation of mathematical model of the microclimate of a greenhouse. Renew Energy 31:154160.

Singh M C, Singh J P, Pandey S K, Mahay D and Srivastava V 2017a. Factors affecting the performance of greenhouse cucumber cultivation-a review. Int J Curr Microbiol App Sci 6:2304-23.

Singh M C, Singh J P, and Singh K G 2017b. Optimal operating microclimatic conditions for drip fertigated cucumbers in soilless media under a naturally ventilated greenhouse. Indian $J$ Ecol 44:821-26.

Singh M C, Yousuf A and Singh J P 2016. Greenhouse microclimate modeling under cropped conditions-A review. Res Environ Life Sci 9:1552-57.

Siwek P and Lipowiecka M 2004. Cucumber cultivation under plastic covers economic results. Folta Hort Ann 16:40-55.

Siwek P, Wojciechowska R, Kalisz A, Libik A and Gryza I 2010. Effect of shading with various colored films on the yield and quality of celery and butter head lettuce. Ecol Chem Eng 17: 1619-27.

Slack G and Hand D W 1981. Control of air temperature for cucumber production. Acta Hort 118:175-86.

Slack G, Fenlon J S and Hand D W 1988. The effects of summer $\mathrm{CO}_{2}$ enrichment and ventilation temperatures on the yield, quality and value of glasshouse tomatoes. J HortSci 63:119-29.

Stanghellini C and Van Meurs W Th M 1992. Environmental control of greenhouse crop transpiration. J Agric Eng Res 51:297311.

Sumathi T, Ponnuswami V and Selvi B S 2008. Anatomical changes of cucumber (Cucumis Sativus L.) leaves and roots as influenced by shade and fertigation. Res $J$ Agri Bio Sci 4:630-38.

Teitel M, Barak M and Zhao Y 2006. Ventilation of a greenhouse with continuous roof and side vents. Acta Hort 719:41-48.

Teitel M, Gahali Y, Barak M, Lemcoff H, Antler A, Wenger E, Amir R, Gantz S and Harhel D 2012. The effect of shading nets on greenhouse microclimate. Acta Hort 952:731-38.

Teitel M, Liran O, Tanny J and Barak M 2008. 
Wind driven ventilation of a mono-span greenhouse with a rose crop and continuous screened side vents and its effect on flow patterns and microclimate. Biosyst Eng 101:111-22.

Tremblay N and Gosselin A 1998. Effect of carbon dioxide enrichment and light. Hort Technol 8:524-28.

Van de Vooren J 1981. Effect of day and night temperatures on earliness and fruit production in cucumber. Acta Hort 118:187-90.

Villarreal-Guerrero F, Flores-Velazquez $\mathrm{J}$ and Kacira M 2014. Comparative performance of a greenhouse cooling strategy with natural ventilation and fogging under different outside climates. Acta Hort 1037:57-64.

Watts D B and Goltz S M 1985. Potato evapotranspiration and yield under limiting and non-limiting water conditions. In: Advances in Evapotranspiration. Proc National Conference on Advances in Evapotranspiration. pp 314-22. ASAE, St. Joseph, MI.

Willits D H 1999. Constraints and limitation in greenhouse cooling. Challenges for the next decade. In: Proceedings of the ISHS International symposium on greenhouse techniques towards the third Millennium, September 5-8.

Willits D H 2003. Cooling fan ventilated greenhouses: a modeling study. Biosyst Eng 84:315-29.

Wilson J W, Hand D W and Hannah M A 1992. Light interception and photosynthetic efficiency in some glasshouse crops. $J$ Exp Bot 43:363-73.

Yang D, Nakano K, Terano D and Yan H 2008. Numerical analysis of microclimate inside four single span greenhouses. Proc World Conference on Agricultural Information and IT. pp 165-73.

Yang X, Short T H, Fox R D and Bauerie W L 1990a. Transpiration, leaf temperature and stomatal resistance of a greenhouse cucumber crop. Agric For Meteorol 51:197-209.

Zhao Y, Teitel M and Barak M 2001. Vertical temperature and humidity gradients in a naturally ventilated greenhouse. J Agric Eng Res 78:431-36.

\section{How to cite this article:}

Mahesh Chand Singh, J.P. Singh, Sandeep Kumar Pandey, Nikhil Gladwin Cutting, Pankaj Sharma, Varun Shrivastav and Puneet Sharma. 2018. A Review of Three Commonly Used Techniques of Controlling Greenhouse Microclimate. Int.J.Curr.Microbiol.App.Sci. 7(01): 3491-3505. doi: https://doi.org/10.20546/ijcmas.2018.701.411 